\title{
Helium effects and bubbles formation in irradiated $\mathrm{Ti}_{3} \mathrm{SiC}_{2}$
}

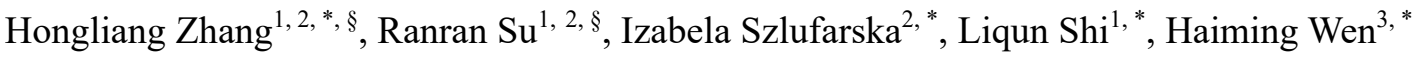 \\ ${ }^{1}$ Institute of Modern Physics, Fudan University, Shanghai, China \\ ${ }^{2}$ Department of Materials Science and Engineering, University of Wisconsin, Madison, WI, \\ 53706, USA \\ ${ }^{3}$ Department of Materials Science and Engineering, Missouri University of Science and \\ Technology, Rolla, U.S.A. \\ $\S$ Co-first authors \\ * Corresponding authors. \\ zhlcanes@hotmail.com (H. Zhang) \\ szlufarska@wisc.edu (I. Szlufarska), \\ lqshi@fudan.edu.cn (L.Q. Shi), \\ wenha@mst.edu (H.M. Wen)
}

\begin{abstract}
$\mathrm{Ti}_{3} \mathrm{SiC}_{2}$ is a potential structural material for nuclear reactor applications. However, $\mathrm{He}$ irradiation effects in this material are not well understood, especially at high temperatures. Here, we compare the effects of $\mathrm{He}$ irradiation in $\mathrm{Ti}_{3} \mathrm{SiC}_{2}$ at room temperature (RT) and at $750{ }^{\circ} \mathrm{C}$. Irradiation at $750{ }^{\circ} \mathrm{C}$ was found to lead to extremely elongated He bubbles that are concentrated in the nano-laminate layers of $\mathrm{Ti}_{3} \mathrm{SiC}_{2}$, whereas the overall crystal structure of the material remained intact. In contrast, at RT, the layered structure was significantly damaged and highly disordered after irradiation. Our study reveals that at elevated temperatures, the unique structure of $\mathrm{Ti}_{3} \mathrm{SiC}_{2}$ can accommodate large amounts of $\mathrm{He}$ atoms in the nano-laminate layer, without compromising the structural stability of the material. The structure and the mechanical tests results show that the irradiation induced swelling and hardening at $750{ }^{\circ} \mathrm{C}$ are much smaller than those at $\mathrm{RT}$. These results indicate that $\mathrm{Ti}_{3} \mathrm{SiC}_{2}$ has an excellent resistance to accumulation of radiation-induced $\mathrm{He}$ impurities and that it has a considerable tolerance to irradiationinduced degradation of mechanical properties at high temperatures.
\end{abstract}

\section{Introduction}

$\mathrm{Ti}_{3} \mathrm{SiC}_{2}$, first synthesized in the 1960s [1], is one of the MAX phase materials, in which $\mathrm{M}$ is an early transition metal element, $\mathrm{A}$ is a group III or IV element, and $\mathrm{X}$ is $\mathrm{C}$ or $\mathrm{N}$. $\mathrm{Ti}_{3} \mathrm{SiC}_{2}$ 
has many excellent properties, including good electrical and thermal conductivities $\left(11 \times 10^{6} \Omega^{-}\right.$ ${ }^{1} \mathrm{~m}^{-1}$ and $43 \mathrm{~W} / \mathrm{m} \mathrm{K}$, respectively) [2-5], high Young's modulus ( 325 GPa) [6], high resistance to thermal shock, and good ductility (above $1100{ }^{\circ} \mathrm{C}$ ) [7]. It has been previously reported, from both experiments and theory, that $\mathrm{Ti}_{3} \mathrm{SiC}_{2}$ exhibits a high resistance to irradiation-induced structural disordering [7-12]. Specifically, under ion irradiation, $\mathrm{Ti}_{3} \mathrm{SiC}_{2}$ was found to remain crystalline even at a very high dose of 116.9 displacements per atom (dpa) [11]. Furthermore, experiments have shown that at temperatures above $400{ }^{\circ} \mathrm{C}, \mathrm{Ti}_{3} \mathrm{SiC}_{2}$ has a better resistance to radiation-induced cracking as compared with other MAX phase materials, such as $\mathrm{Ti}_{3} \mathrm{AlC}_{2}$ and $\mathrm{Ti}_{2} \mathrm{AlC}[9,12,13]$.

Thanks to the above properties, $\mathrm{Ti}_{3} \mathrm{SiC}_{2}$ could be potentially used as a structural material in Gen IV fission and fusion reactors where materials are exposed to high temperatures and intense neutron irradiation. For these applications, it is important to consider the behavior of He atoms, introduced either by radiation or by transmutation through the (n, $\alpha)$ nuclear reaction. In many materials, He atoms are known to interact with lattice vacancies, forming He-vacancy clusters, and eventually growing into He bubbles [14]. Once the He bubbles grow to a certain size (i.e., have a critical volume), they will rupture, causing the material to peel and flake off, which in turn will have a significant effect on mechanical properties of the material [15-17]. There have been several studies on the He irradiation of $\mathrm{Ti}_{3} \mathrm{SiC}_{2}$ [18-20], however, most of them are at RT. The only high-temperature study was at $450{ }^{\circ} \mathrm{C}$, in which the irradiated $\mathrm{Ti}_{3} \mathrm{SiC}_{2}$ was analyzed by grazing incidence X-ray diffraction (GIXRD) [19]. The results showed smaller anisotropic swelling and less damage as compared to those at RT. However, the morphology and distribution of He bubbles were not studied in Ref. [19]. Some He irradiation studies at elevated temperatures have been reported for other MAX phases. For instance, the authors of Refs. [21-23] observed the morphology of He bubbles in He-irradiated $\mathrm{Ti}_{2} \mathrm{AlC}$ and $\mathrm{Ti}_{3} \mathrm{AlC}_{2}$ by bright-field transmission electron microscopy (TEM). However, due to the limitation of the resolution, the clear shapes of the He bubbles and their positions in the lattice could not be clearly identified. Elongated He bubbles were mentioned in Ref. [24], but the paper was focused on the radiation-induced phase transformation. In general, understanding of shapes and positions of He bubbles in MAX phases at elevated temperatures is still limited. In addition, 
the relationships between the morphology and distribution of He bubbles and the changes of the microstructure and in the mechanical properties at different temperatures have not been reported so far.

In this paper, we report a comparative study of high temperature and RT He irradiation in $\mathrm{Ti}_{3} \mathrm{SiC}_{2}$. Structural changes in irradiated $\mathrm{Ti}_{3} \mathrm{SiC}_{2}$ samples were analyzed with GIXRD and Rietveld refinements. The near-surface changes in the irradiated samples were characterized using Raman spectroscopy. Radiation-induced changes in mechanical properties (hardness and Young's modulus) were studied using nanoindentation. Changes in the microstructure and the He bubble morphology for samples irradiated at different temperatures were investigated using TEM. In particular, $\mathrm{Ti}_{3} \mathrm{SiC}_{2}$ structure consists of $\mathrm{Ti}-\mathrm{C}$ layers interlaid with $\mathrm{Si}$ layers. The role of the layered structures in $\mathrm{Ti}_{3} \mathrm{SiC}_{2}$ in accommodating damage during He irradiation is also analyzed in this study using TEM and high resolution TEM.

\section{Experimental Methods}

The material used in this work was polycrystalline bulk $\mathrm{Ti}_{3} \mathrm{SiC}_{2}$, prepared by reactive sintering. Stoichiometric mixtures of $3 \mathrm{Ti}+\mathrm{SiC}+\mathrm{C}$ were prepared by hand grinding fine $\mathrm{Ti}$ (99.9\%), SiC (99.9\%), and C (graphite, 99.99\%) powders under argon, followed by cold pressing in a hardened steel die at $180 \mathrm{MPa}$. The powders contained $\sim 2 \mathrm{wt} . \% \mathrm{Al}$ to assist with reactivity. The pressed cylindrical samples were sintered under flowing argon gas by heating to $1600^{\circ} \mathrm{C}$ at $10^{\circ} \mathrm{C} \mathrm{min}^{-1}$, holding for $4 \mathrm{~h}$, and returning to RT. During sintering, a small amount of $\mathrm{Al}_{2} \mathrm{O}_{3}$ was formed in the sample. The as-sintered specimens were polished using fine metallographic abrasive paper and $\mathrm{Al}_{2} \mathrm{O}_{3}$ suspensions, cleaned by rinsing in ultrasonic baths of acetone and ethanol, and annealed at $800^{\circ} \mathrm{C}$ in a vacuum environment of $5 \times 10^{-5} \mathrm{~Pa}$ for $1 \mathrm{~h}$ to release residual stress.

The final $\mathrm{Ti}_{3} \mathrm{SiC}_{2}$ bulk samples were irradiated with $110 \mathrm{keV} \mathrm{He}^{+}$beam incident at $0^{\circ}$ to the normal using the tandem accelerator at Institute of Applied Physics, Chinese Academy of Science [25]. The typical irradiation flux was kept at $\sim 7.0 \times 10^{11}$ ions $\cdot \mathrm{cm}^{-2} \cdot \mathrm{s}^{-2}$. The irradiation fluence delivered to the samples was $5 \times 10^{16}$ ions $\cdot \mathrm{cm}^{-2}$ and the background pressure during irradiation was $<5 \times 10^{-4} \mathrm{~Pa}$. The total damage, measured in terms of dpa, was simulated using 
SRIM-2013 [26], with displacement energies of 25, 15, and $28 \mathrm{eV}$ for Ti, $\mathrm{Si}$, and C, respectively, and with an average atomic density for $\mathrm{Ti}_{3} \mathrm{SiC}_{2}$ of $8.34 \times 10^{22}$ atoms $\cdot \mathrm{cm}^{-3}$. The damage level obtained from the SRIM-2013 simulation was estimated to be $0.5 \mathrm{dpa}$ at the surface, rising to 2.8 dpa at a depth of $400 \mathrm{~nm}$ as shown in Fig. 1.

GIXRD data were obtained at beam line BL14B1 of the Shanghai Synchrotron Radiation Facility at a wavelength of $1.2398 \AA$. The size of the focus spot was $\sim 0.5 \mathrm{~mm}$ and the end station was equipped with a Huber 5021 diffractometer. The diffraction data were analyzed using a Rietveld analysis program (Rietica 7.1). From the Rietveld refinement, the $\mathrm{Ti}_{3} \mathrm{SiC}_{2}$ phase was clearly identified from the sharp peaks at the relevant diffraction angles. The damaged component was identified by broader and slightly displaced peaks from the $\mathrm{Ti}_{3} \mathrm{SiC}_{2}$ peaks. The uncertainties in the phase compositions and lattice parameter were typically $1-2 \%$ and $0.5 \%$, respectively.

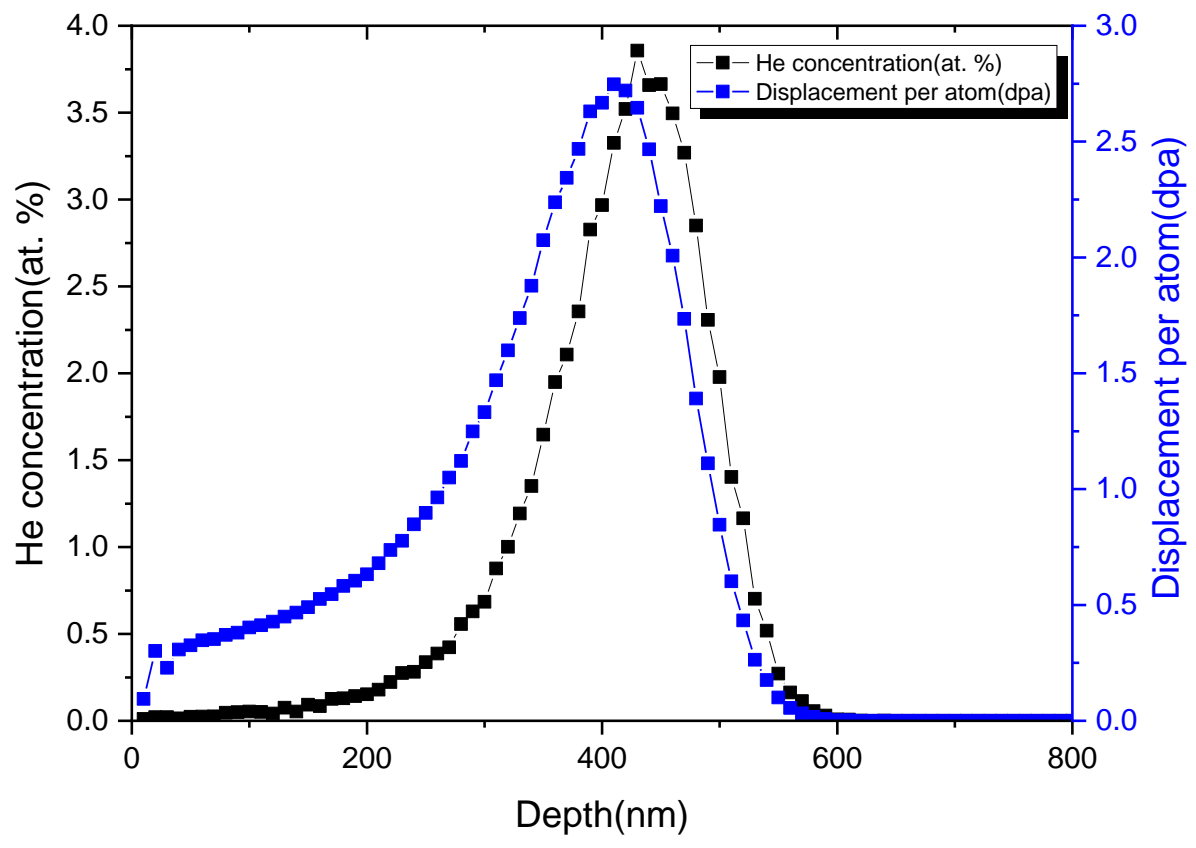

Fig. 1 He atom concentration and radiation damage in dpa for $\mathrm{Ti}_{3} \mathrm{SiC}_{2}$ irradiated with $5 \times 10^{16} \mathrm{~cm}^{-2}$ simulated by SRIM 2013 .

Raman spectroscopy was performed on a XploRA Laser Raman spectrometer produced by HORIBA Jobin Yvon. The measurements were conducted using a $632.8 \mathrm{~nm}$ wave-length laser with a detection range from 100 to $1900 \mathrm{~cm}^{-1}$ and a total acquisition time of $100 \mathrm{~s}$. The 
spectrum resolution was better than $2 \mathrm{~cm}^{-1}$. The Raman signal is known to decay exponentially as a function of the distance from the surface, with a decay length of approximately $10 \mathrm{~nm}$. The Raman spectroscopy should, therefore, be sensitive to the surface region.

The hardness and modulus of the samples were measured using Hysitron TI-950 Tribo Indenter Nanoindenter and Atomic Force Microscope (AFM) at room temperature with a nano indenter by the continuous stiffness measurement (CSM) mode equipped with a diamond Berkovich indenter (triangular based pyramid). The depth of the indentation is about $500 \mathrm{~nm}$. 10 indentations were performed for each sample and the results were averaged over the ten measurements. The real shape of the indenter was calibrated by the standard method that involves indenting a fused silica sample at different normal loads.

In order to characterize the evolution of the He bubbles, the topography, and the microstructural evolution of the samples, TEM observations were carried out using a FEI Tecnai G2 F30 transmission electron microscope, in the Institute of Metal Research, Chinese Academy of Science. Cross-sectional TEM samples were prepared using mechanical polishing and then ion milling to form a wedge to create sufficient electron transparency.

\section{Results}

Structural changes and lattice swelling after irradiation were characterized by GIXRD and refinement. Fig.2 shows the GIXRD patterns and the refinement results for the unirradiated $\mathrm{Ti}_{3} \mathrm{SiC}_{2}$ sample and from samples irradiated at $\mathrm{RT}$ and at $750{ }^{\circ} \mathrm{C} . \mathrm{X}$-ray incident angle was $1.5^{\circ}$, corresponding to the penetration depth of $457 \mathrm{~nm}$, which is close to the helium irradiation depth range.

Compared to the unirradiated sample's pattern, the pattern for the RT sample shows a clear increase in the background signal, a significant decrease in the peak intensity, and a notable broadening of the peaks. These changes suggest a decrease in the crystallinity of the lattice. There is also a small shift of the peak positions to the low angle direction, indicating an expansion in the unit cell after helium irradiation. The refinement results showed that the $c$ lattice parameter increased from 17.65 to $17.95 \AA$, which was an increase of approximately $1.70 \%$. On the other hand, the $a$ lattice parameter remained almost unchanged at $3.06 \AA$. This 
is in good agreement with previous RT-irradiation result [18], which showed an increased $c$ lattice parameter of $17.9 \AA$ and an almost unchanged $a$ lattice parameter of $3.06 \AA$. It is possible that the increase of the $c$ lattice parameter mostly comes from the lattice expansion induced by the He bubbles and clusters.

The $750{ }^{\circ} \mathrm{C}$ irradiated sample exhibits a much higher crystallinity level compared with the RT one. The pattern is almost identical to that of the unirradiated sample. The $c$ lattice parameter increases slightly from 17.65 to $17.70 \AA$, which is only by $0.3 \%$. In the previous study, where $\mathrm{Ti}_{3} \mathrm{SiC}_{2}$ was irradiated by $\mathrm{He}$ ion at $450{ }^{\circ} \mathrm{C}$ [19], Rietveld refinement showed a $c$ lattice parameter of $17.81 \AA$. Therefore, the swelling along the $c$ direction at $750{ }^{\circ} \mathrm{C}$ is smaller than that at $450{ }^{\circ} \mathrm{C}$. The results indicate that $\mathrm{Ti}_{3} \mathrm{SiC}_{2}$ has a very good tolerance to swelling induced by $\mathrm{He}$ irradiation at a higher temperature of $750{ }^{\circ} \mathrm{C}$, underscoring the potential of $\mathrm{Ti}_{3} \mathrm{SiC}_{2}$ as cladding and structure materials at this temperature.

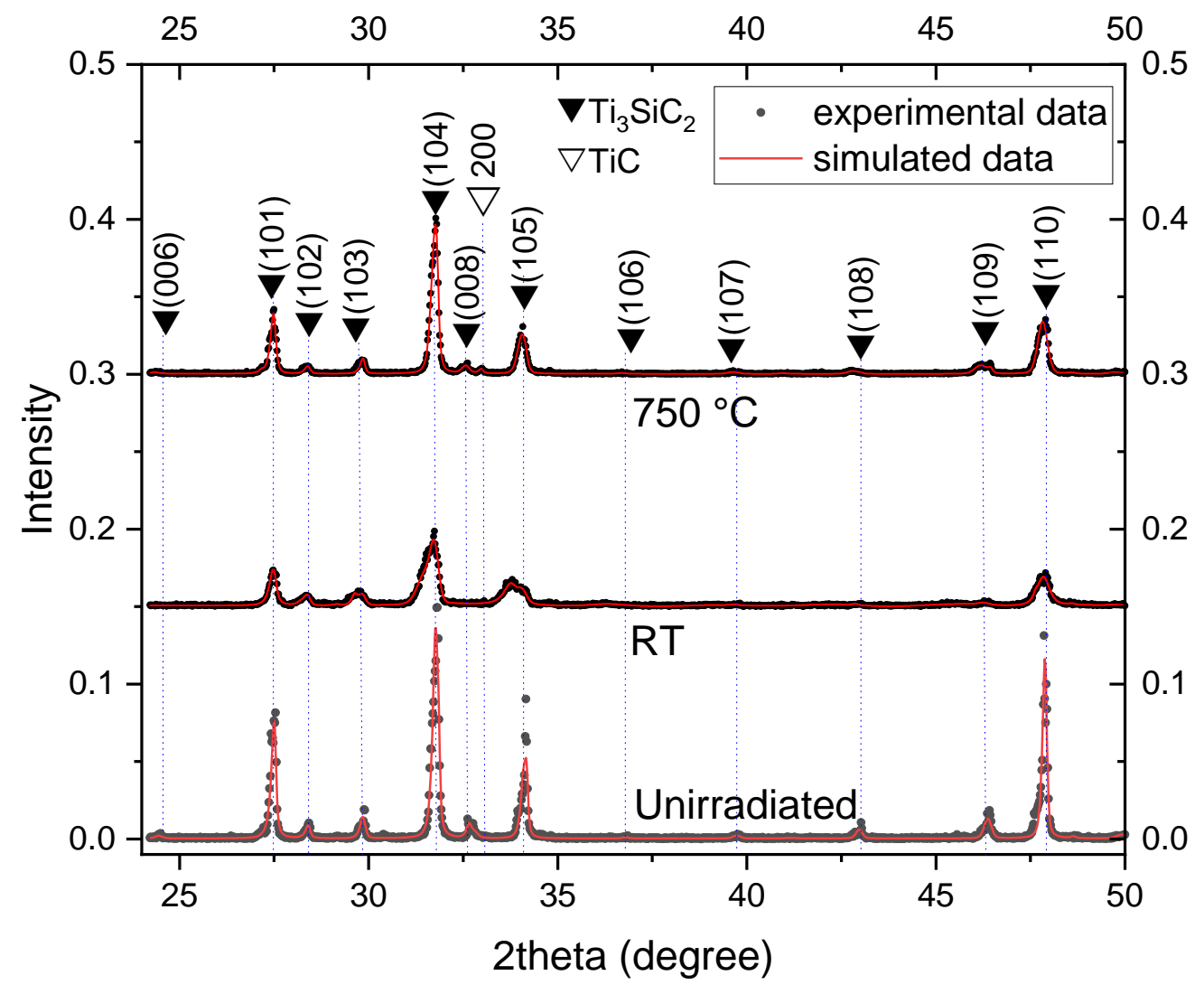

Fig.2 GIXRD and refinements results for samples unirradiated, irradiated at $R T$ and $750{ }^{\circ} \mathrm{C}$. One phase ( $\mathrm{Ti}_{3} \mathrm{SiC}_{2}$ undamaged phase) was used to refine the spectrum of unirradiated $\mathrm{Ti}_{3} \mathrm{SiC}_{2}$. Three phases were used to do the refinement of the spectra of $R T$ and $750^{\circ} \mathrm{C}$ irradiated samples: 
(i) $\mathrm{TiC}$ phase (to represent $\mathrm{TiC}$ or fcc-( $\left.\mathrm{Ti}_{3} \mathrm{Si}\right) \mathrm{C}_{2}$ ), (ii) $\mathrm{Ti}_{3} \mathrm{SiC}_{2}$ undamaged phase, and (iii) $\mathrm{Ti}_{3} \mathrm{SiC}_{2}$ damaged phase. The red lined spectra are the simulated spectra based on the experimental data.

The near surface damage was analyzed by Raman spectroscopy. Spectra collected for the unirradiated and irradiated $\mathrm{Ti}_{3} \mathrm{SiC}_{2}$ samples are shown in Fig. 3. The spectrum of the unirradiated sample has six peaks at 159,228, 281,312,631, and $678 \mathrm{~cm}^{-1}$, which corresponds to $\mathrm{Ti}_{3} \mathrm{SiC}_{2}[27,28]$. After helium irradiation at $\mathrm{RT}$, all these peaks disappear. Two notable peaks are located at $\sim 1335$ and $1580 \mathrm{~cm}^{-1}$ in the spectrum, which are associated with the $\mathrm{A}_{1 \mathrm{~g}}$ and the $\mathrm{E}_{2 \mathrm{~g}}$ vibrational modes of graphite. These results are in good agreement with previous studies, which reported disappearance of $\mathrm{Ti}_{3} \mathrm{SiC}_{2}$ related peaks and appearance of graphite related peaks $[19,28]$. These changes imply a significant surface damage. Two small TiC-related peaks located at 386 and $590 \mathrm{~cm}^{-1}$ (shown as red dashed lines) are found in the Raman spectra, suggesting that there is a small amount of $\mathrm{TiC}_{\mathrm{x}}$ in the near surface region. In contrast, for the $750{ }^{\circ} \mathrm{C}$ irradiated $\mathrm{Ti}_{3} \mathrm{SiC}_{2}$, the spectrum is almost the same as that for the unirradiated sample, and all peaks corresponding to $\mathrm{Ti}_{3} \mathrm{SiC}_{2}$ are still present in the spectrum. Peaks associated with the $\mathrm{A}_{1 \mathrm{~g}}$ and the $\mathrm{E}_{2 \mathrm{~g}}$ vibrational modes of graphite are also visible in the $750{ }^{\circ} \mathrm{C}$ irradiated $\mathrm{Ti}_{3} \mathrm{SiC}_{2}$ spectrum. These two peaks were possibly caused by carbon contamination in the background vacuum system during helium irradiation. Since the Raman spectroscopy analysis only detects the state of a surface region, the results indicate that the surface region exhibits good crystallinity at an irradiation temperature of $750{ }^{\circ} \mathrm{C}$, and that $\mathrm{Ti}_{3} \mathrm{SiC}_{2}$ has much better tolerance to surface damage for irradiation at $750{ }^{\circ} \mathrm{C}$ than at RT. 


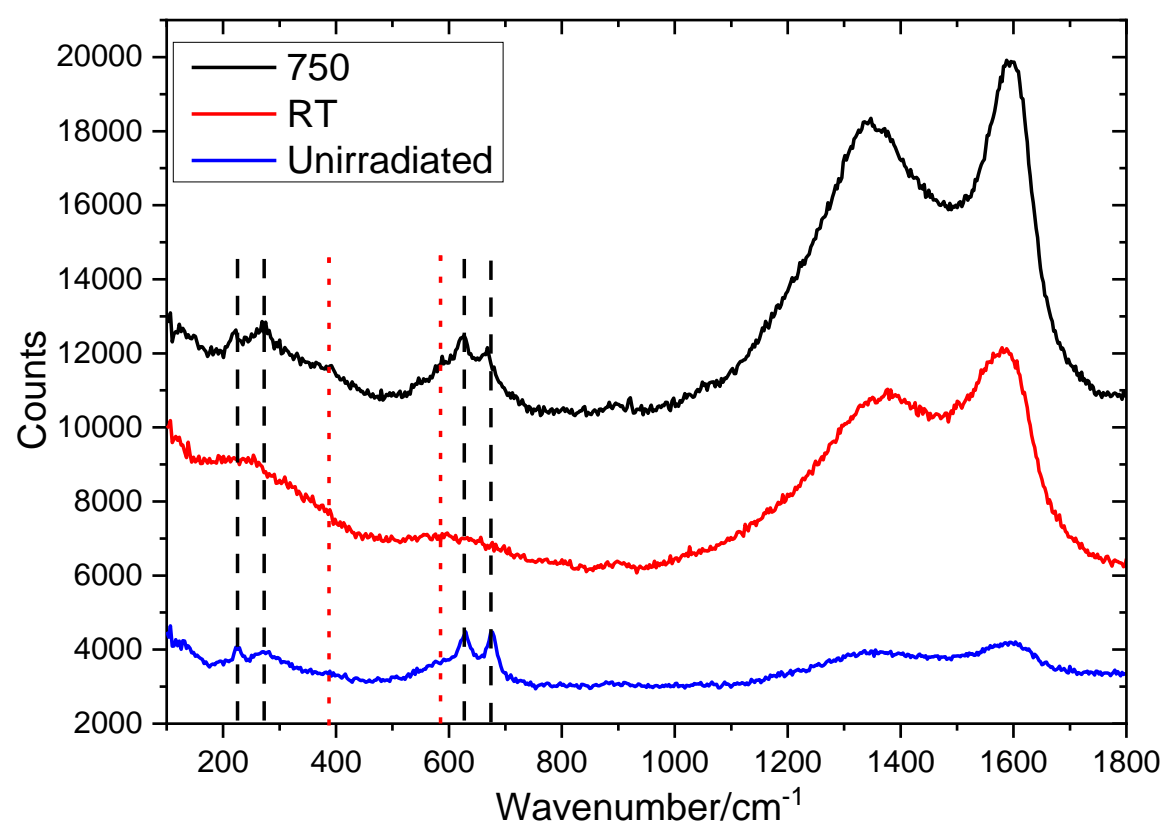

Fig.3 Raman spectra for unirradiated sample, samples irradiated at $R T$ and $750^{\circ} \mathrm{C}$

Hardness and Young's modulus before and after irradiation were measured by nano indentation and are shown in Fig. 4. The hardness of $\mathrm{Ti}_{3} \mathrm{SiC}_{2}$ changes from 6.68 to $9.96 \mathrm{GPa}$ after RT irradiation, with a significant increase of $49.1 \%$. However, when irradiated at $750^{\circ} \mathrm{C}$ with the same irradiation fluence, the hardness only changes from 6.68 to $7.21 \mathrm{GPa}$, with an increase of $7.93 \%$. In contrast to hardness, Young's modulus decreases due to irradiation. For the RT irradiated sample, the Young's modulus drops from 186.51 to $130.11 \mathrm{GPa}$, with a decrease of $>30.2 \%$. For the $750^{\circ} \mathrm{C}$ irradiated sample, Young's modulus drops from 186.51 to 167.65 GPa, with a decrease of $\sim 10.1 \%$. For the $750{ }^{\circ} \mathrm{C}$ irradiated sample, the changes in the hardness and Young's modulus are much smaller than those for the RT irradiated sample, which confirms that the $\mathrm{Ti}_{3} \mathrm{SiC}_{2}$ has better tolerance for irradiation induced mechanical properties change at $750{ }^{\circ} \mathrm{C}$ than that at $\mathrm{RT}$, although changes of $\sim 8-10 \%$ in mechanical properties observed at $750{ }^{\circ} \mathrm{C}$ are not insignificant. 


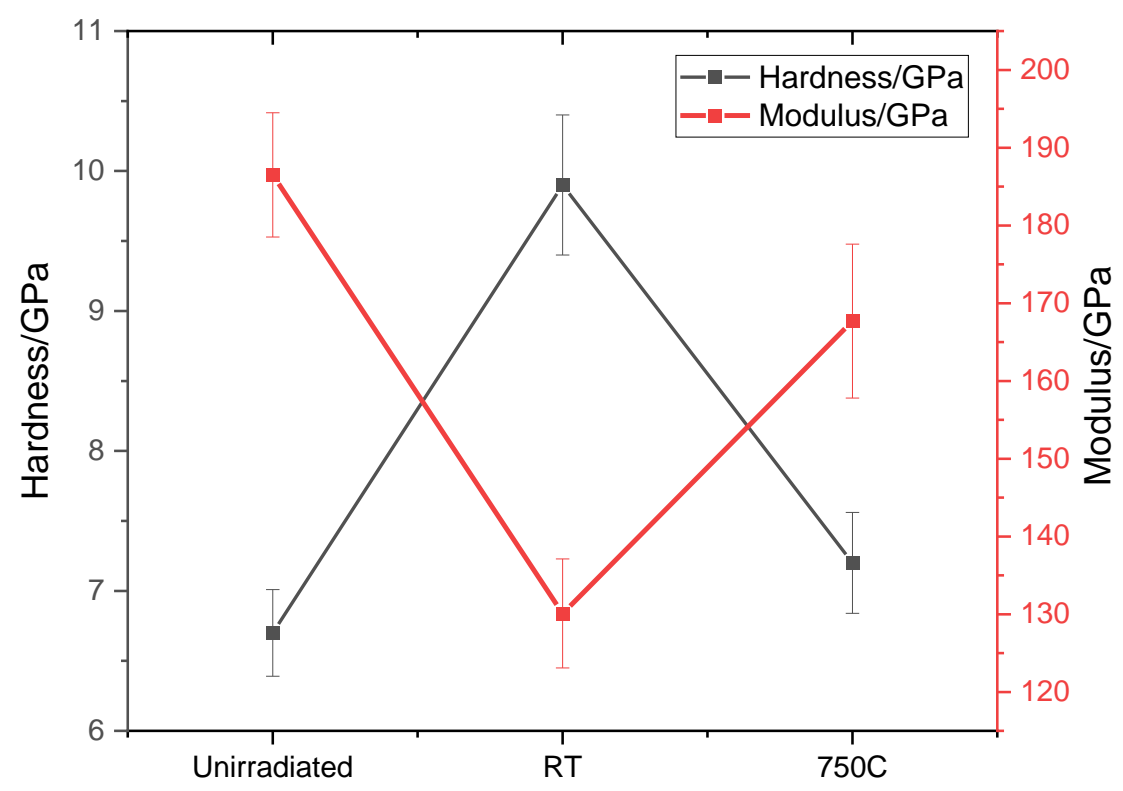

Fig.4 Hardness and Young's modulus of the unirradiated sample and the samples irradiated at $R T$ and $750^{\circ} \mathrm{C}$
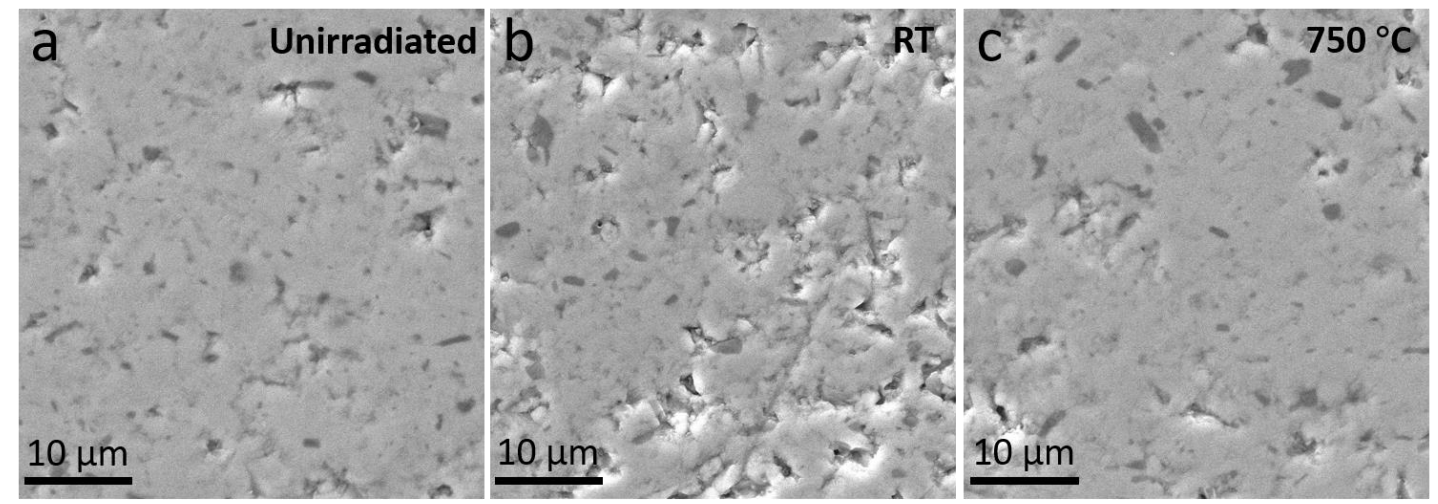

Fig. 5 SEM images of (a) unirradiated $\mathrm{Ti}_{3} \mathrm{SiC}_{2}$, and $\mathrm{Ti}_{3} \mathrm{SiC}_{2}$ irradiated at (b) $\mathrm{RT}$, and (c) $750{ }^{\circ} \mathrm{C}$.

Fig. 5 shows the SEM images of the unirradiated and irradiated $\mathrm{Ti}_{3} \mathrm{SiC}_{2}$ samples. The darker spots are $\mathrm{Al}_{3} \mathrm{O}_{2}$, which was introduced by $\mathrm{Al}$ doping during the sample fabrication using the reactive sintering method. Unlike $\mathrm{Ti}_{3} \mathrm{AlC}_{2}$ and $\mathrm{Ti}_{2} \mathrm{AlC}$, which show a high density of cracks after RT irradiation $[9,23,24]$, the surface of $\mathrm{Ti}_{3} \mathrm{SiC}_{2}$ is free of cracks at both $\mathrm{RT}$ and $750{ }^{\circ} \mathrm{C}$, suggesting that $\mathrm{Ti}_{3} \mathrm{SiC}_{2}$ has a better resistance to irradiation-induced surface cracks.

In order to analyze the morphology and the distribution of He bubbles as well as to analyze the irradiated $\mathrm{Ti}_{3} \mathrm{SiC}_{2}$ in TEM, bright field TEM images of the $\mathrm{Ti}_{3} \mathrm{SiC}_{2}$ after irradiation at $\mathrm{RT}$ 
and at $750^{\circ} \mathrm{C}$ from [11-20] are shown in Figs. $6 \mathrm{a}$ and $6 \mathrm{~b}$, respectively. In the RT-irradiated sample, most of the helium bubbles are spherical in shape, with diameters of $\sim 1-2 \mathrm{~nm}$. The He bubbles are densely distributed in the irradiated area. In the $750^{\circ} \mathrm{C}$-irradiated sample, $\mathrm{He}$ bubbles exhibit very different shape; most of them are columnar with a very long axis and a small cross section. More specifically, the diameter for most of the helium bubbles is $<1 \mathrm{~nm}$, whereas the length is $>15 \mathrm{~nm}$, with some bubbles as long as $40 \mathrm{~nm}$. Moreover, the amount of He bubbles was found to increase monotonically with the dpa. The density of He bubbles is the highest in the damage peak region and the lowest in the near-surface region. In addition, as shown in Fig. 6c, helium bubbles are distributed parallel to the nano-layer direction. The results indicate the structure of $\mathrm{Ti}_{3} \mathrm{SiC}_{2}$ has a great ability to impede the free growth of the He bubbles at elevated temperatures and therefore has a high resistance to irradiation-induced swelling during the He irradiation and He evolution. Fig. 6d shows the morphology and distribution of helium bubbles at a grain boundary in the $750{ }^{\circ} \mathrm{C}$-irradiated sample. Density of the helium bubbles is evidently higher at the grain boundary than in the grain interiors. The helium bubbles still exhibit a columnar shape at the grain boundary. There is an obvious depleted zone of $\sim 100$ $\mathrm{nm}$ between the He bubbles in the GB region and in the bulk region. According to our TEM observations, when the dose is larger than $0.5 \mathrm{dpa}$, the effects of the irradiation depths and of the specific value of dpa on the shape of He bubbles are very small. The main factor that controls the shape of He bubbles is the irradiation temperature. When the temperature reaches $750{ }^{\circ} \mathrm{C}$, the shape of the He bubbles will be elongated. These results show that the He bubbles preferentially concentrate at defects such as grain boundaries. 

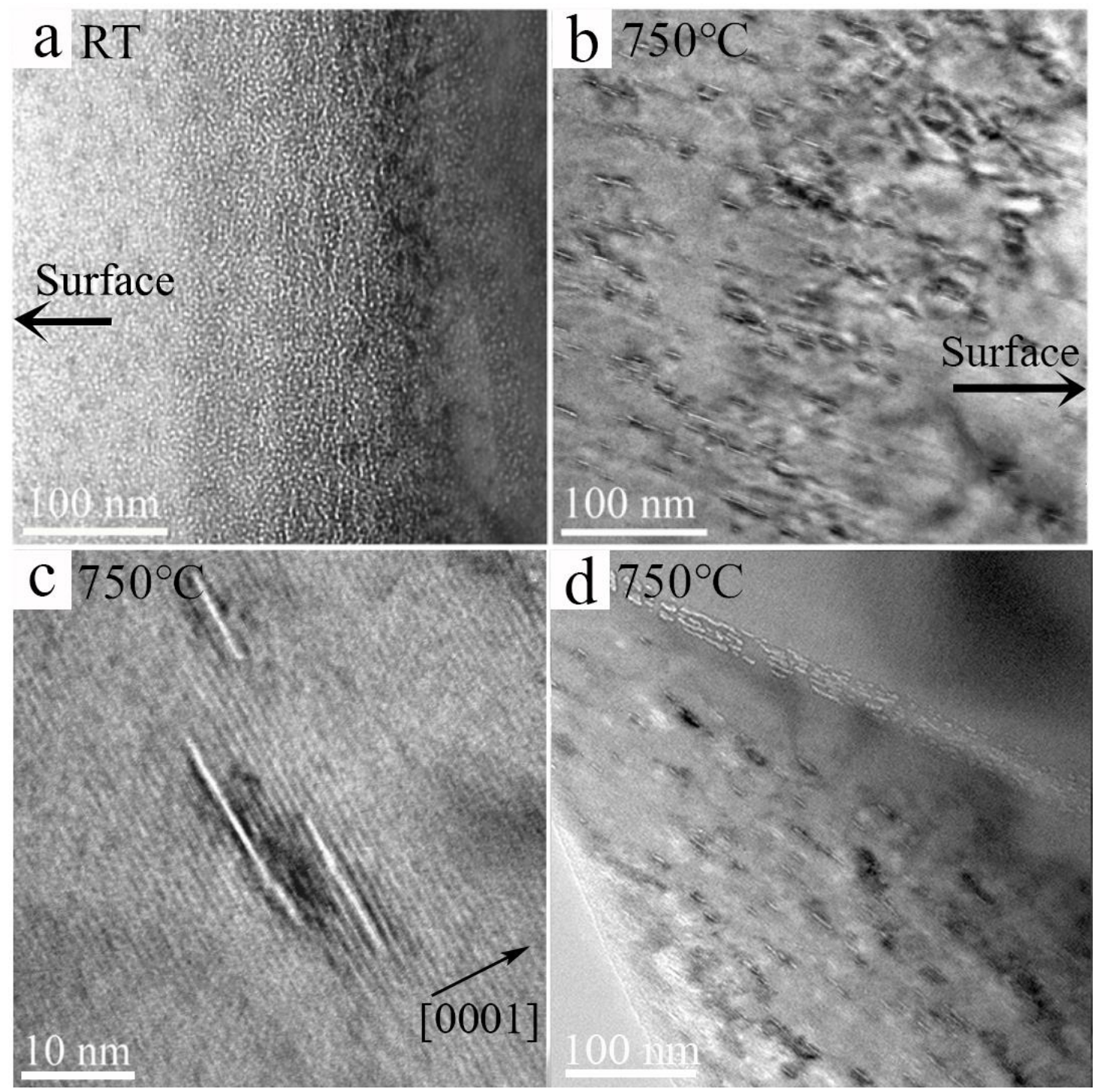

Fig.6 TEM image of the $\mathrm{Ti}_{3} \mathrm{SiC}_{2}$ samples, observed from [11-20], irradiated at (a) RT, the white spots are He bubbles, the black region is the damage peak region which has a high density of black spots defects and (b) $750^{\circ} \mathrm{C}$. (c) HRTEM of the $\mathrm{Ti}_{3} \mathrm{SiC}_{2}$ samples irradiated at $750{ }^{\circ} \mathrm{C}$ showing a He bubble located in the bulk and aligned parallel to basal plane. (d) TEM image of the $\mathrm{Ti}_{3} \mathrm{SiC}_{2}$ samples irradiated at $750{ }^{\circ} \mathrm{C}$ with a grain boundary, showing a zone depleted in He bubbles.

\section{Discussion}

\subsection{Irradiation induced hardening}

The hardness of the $\mathrm{Ti}_{3} \mathrm{SiC}_{2}$ irradiated at $\mathrm{RT}$ and at $750^{\circ} \mathrm{C}$ increased compared with that of the unirradiated sample. The hardness change for the $\mathrm{Ti}_{3} \mathrm{SiC}_{2}$ irradiated at $750^{\circ} \mathrm{C}$ was smaller than that for the RT irradiation. A possible mechanism underlying the radiation-induced hardening is dispersed barrier hardening [29], where radiation induced defects (such as 
vacancies or interstitial clusters) act as barriers to movement of dislocations. For the $\mathrm{He}$ irradiated $\mathrm{Ti}_{3} \mathrm{SiC}_{2}$, the irradiation-induced hardening could come from helium bubbles as well as the $\mathrm{He}$ atoms and clusters.

For the He bubbles, the effect of the bubble formation on hardness can be captured by the following relation $[30,31]$ :

$$
\Delta H=3 \Delta \sigma_{\text {cavity }}=1 / 8 M G b d N^{2 / 3}
$$

where $\Delta H$ is the change of the hardness due to irradiation, $\Delta \sigma_{\text {cavity }}$ is the change in strength induced by bubbles, $M$ is the Taylor factor reflecting crystal orientation, $G$ is the shear modulus (GPa), $b$ is the length of the Burgers vector (nm) of the dislocation, $d$ is the cavity diameter $(\mathrm{nm})$, and $N$ is the cavity density $\left(\mathrm{m}^{-3}\right)$. The density of the helium bubbles was determined by counting the number of $\mathrm{He}$ bubbles at the same depth in the RT and $750{ }^{\circ} \mathrm{C}$ irradiated samples in an area of $50 \mathrm{~nm} \times 50 \mathrm{~nm}$ and then dividing the number of bubbles by the product of area and assumed thickness $(80 \mathrm{~nm})$. The density of the helium bubbles in the $750{ }^{\circ} \mathrm{C}$ and RT irradiated samples are significantly different from each other and they are $\sim 5.0 \times 10^{24} \mathrm{~m}^{-3}$ for RT-irradiated sample (with an average size of $1 \mathrm{~nm}$ ) and $\sim 1.0 \times 10^{23} \mathrm{~m}^{-3}$ for the $750{ }^{\circ} \mathrm{C}$-irradiated sample (with an average size of $15 \mathrm{~nm}$ in the longer direction; since He bubbles are elongated, $15 \mathrm{~nm}$ is the upper limit and a significant overestimate of the bubble size). According to the equation above, the product of $d \cdot N^{2 / 3}$ is much higher in the RT-irradiated sample than in the $750{ }^{\circ} \mathrm{C}$-irradiated sample, which can explain a more significant hardness increase. This is one of the reasons for the much higher irradiation-induced hardening in $\mathrm{Ti}_{3} \mathrm{SiC}_{2}$ irradiated at $\mathrm{RT}$.

Although many helium atoms bind to vacancies to form helium bubbles in the irradiated area, there are still large number of isolated helium atoms or helium clusters in the RT-irradiated sample [26-27]. A fluence of $5 \times 10^{16} \mathrm{~cm}^{-2} \mathrm{He}$ into a $100 \mathrm{~nm}$ depth range corresponds to a $\mathrm{He}$ density of $5 \times 10^{27} \mathrm{~m}^{-3}$ at the peak region. The number density of the He bubbles in this region can be estimated using the relationship between the He bubble pressure and the number of $\mathrm{He}$ atoms [34]:

$$
P=4.83 \times 10^{2} \exp \left(5.15 \times 10^{-23} \rho\right) \mathrm{atm}
$$

where $P$ is the pressure of the helium bubble and $\rho$ is the He bubble density in the units of $\mathrm{He}$ atoms $/ \mathrm{m}^{3}$. Assuming a bubble pressure of $10 \mathrm{GPa}[35,36]$, we can estimate that each $1.0 \mathrm{~nm}$ 
diameter bubble contains approximately $500 \mathrm{He}$ atoms, which predicts the bubble density of 1 $\times 10^{25} \mathrm{~m}^{-3}$ while the actual He bubble density determined from the TEM images is only $\sim 5 \times$ $10^{24} \mathrm{~m}^{-3}$. This analysis indicates that in addition to the He bubbles, there are large number of isolated helium atoms and helium clusters in the RT-irradiated sample. Previous studies have shown that high concentrations of helium interstitials can lead to noticeable hardening, especially when the helium irradiation dose reaches the dpa higher than 1.0 [29-30]. The large amount of isolated helium atoms and clusters are another reason for the higher hardness in the $\mathrm{RT}$ irradiated $\mathrm{Ti}_{3} \mathrm{SiC}_{2}$.

\subsection{The relationship between irradiation temperature and characteristics of helium}

\section{bubbles}
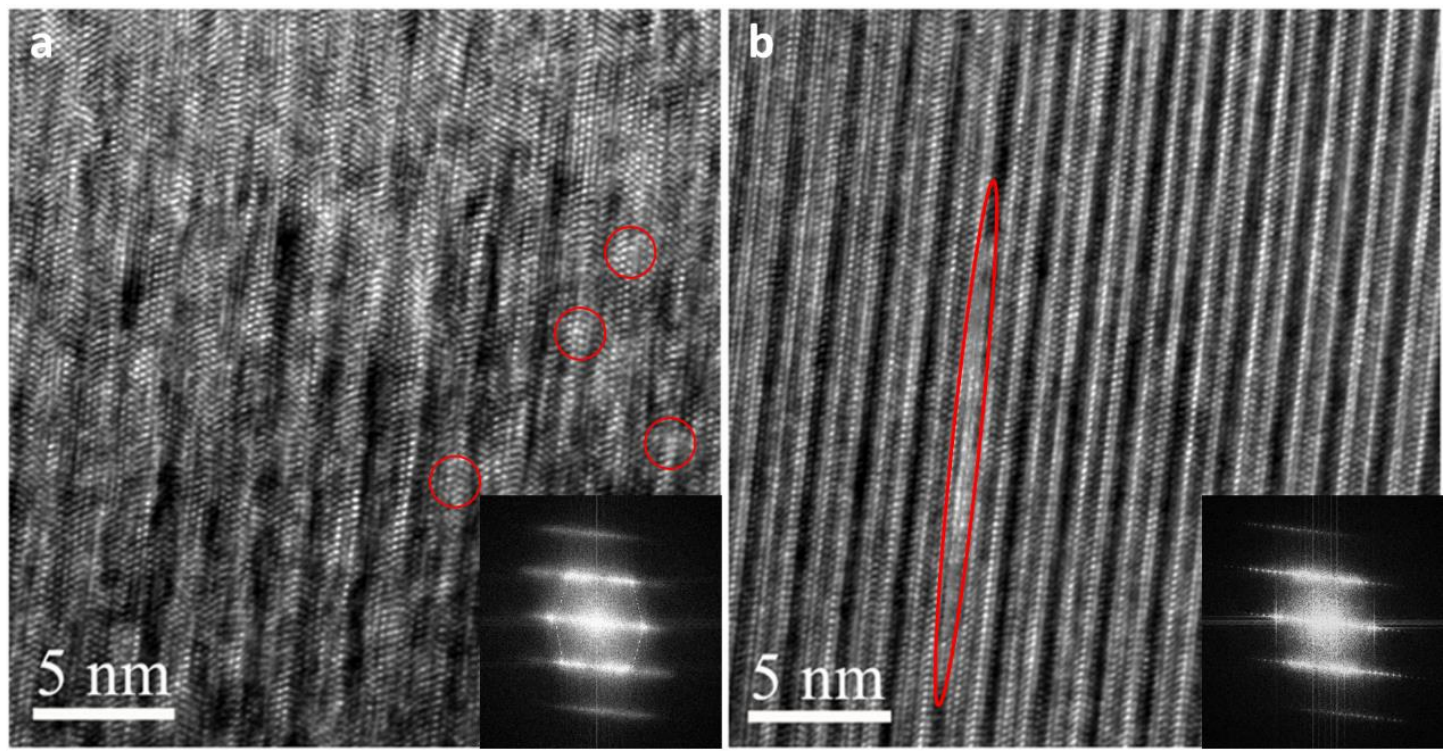

Fig. 7 HRTEM and the corresponded fast Fourier transform (FFT) patterns of the $\mathrm{Ti}_{3} \mathrm{SiC}_{2}$ samples, viewed from [11-20], irradiated at (a) RT showing the disorder of the layer structure in the He bubbles(red circles) region and (b) at $750{ }^{\circ} \mathrm{C}$ showing a He bubble(red oval) located between the layers while the layer structure remained intact.

In the RT irradiated sample, the helium bubbles had a spherical shape, a size of $\sim 1 \mathrm{~nm}$, and they were randomly distributed. In addition, the nano-laminate layered structure of $\mathrm{Ti}_{3} \mathrm{SiC}_{2}$ was found to be severely damaged, as shown in Fig. 7a. The FFT pattern also indicates a significantly damage because of the distortion and disappearance of some diffraction spots, as well as the hexagonal outline in the center of the FFT pattern (marked in the dashed lines). The formation of the small-sized, spherical He bubbles at RT is mainly due to the He implantation 
and redistribution. The helium redistribution at RT is mostly driven by cascade-collisioninduced atomic displacements [37]. These displacements are randomly located in the damage peak region, and the displacement range is usually very small. Consequently, the $\mathrm{He}$ redistribution distance is very limited. As a result, He bubbles can only absorb helium atoms and clusters located very close to them and grow into small bubbles (here with diameters of only $\sim 1 \mathrm{~nm}$ ). These He bubbles are randomly distributed between $\mathrm{Ti}, \mathrm{Si}$, and $\mathrm{C}$ planes. First principle calculations of single $\mathrm{He}$ atom in $\mathrm{Ti}_{3} \mathrm{SiC}_{2}$ have shown that at higher temperatures $\left(>500^{\circ} \mathrm{C}\right) \mathrm{He}$ atoms will quickly migrate into the Si layer whereas at RT some of them will be trapped by vacancies in the C layer and Ti layer [39]. Thus, at RT, the trapped He atoms in C and Ti layers may not have enough energy to detrap and move to the Si layer. Instead, they can bind nearby $\mathrm{He}$ atoms, forming He bubbles.

In the $750^{\circ} \mathrm{C}$ irradiated sample, as mentioned before, He bubbles are much more elongated and have a lower density. In addition, these helium bubbles are located between the layers and are oriented parallel to the nano-laminate layer of the $\mathrm{Ti}_{3} \mathrm{SiC}_{2}$ while the layer-structure remains intact (Fig. 6c and Fig. 7b). The FFT pattern showing clear diffraction spots indicates the higher preservation of the crystallinity than that at RT. There are several reasons for the growth and the evident shape change of the helium bubbles at this elevated temperature. First, a previous study has shown that the formation energy of a He interstitial in the Si layer is $2.99 \mathrm{eV}$, which is lower than the He interstitial formation energy in the $\mathrm{C}$ layer $(3.11 \mathrm{eV})$ and in the Ti layer $(5.10 \mathrm{eV})[40]$, which means that He atoms prefer to stay in Si planes. In addition, the diffusion barrier for He atoms in the $\mathrm{Si}$ layer is only $1.17 \mathrm{eV}$ (and it is the lowest among the different layers), He atoms can migrate in the Si layer at the temperatures above $500{ }^{\circ} \mathrm{C}$ [39]. These calculations have also indicated that $\mathrm{He}$ atoms in other layers will quickly migrate into the $\mathrm{Si}$ layer at higher temperatures $\left(>500{ }^{\circ} \mathrm{C}\right)[39,41,42]$. Therefore, at $750{ }^{\circ} \mathrm{C}$, the He atoms and clusters that might have formed in the $\mathrm{Ti}$ and $\mathrm{C}$ layers, will migrate to the $\mathrm{Si}$ layers and then diffuse within this layer [37] until they are finally retrapped by another He bubble or vacancy. Hence, at $750{ }^{\circ} \mathrm{C}$, a large fraction of helium atoms, clusters and bubbles gather in this layer, and can form the extremely elongated helium bubbles. 


\section{Conclusions}

Helium irradiation of $\mathrm{Ti}_{3} \mathrm{SiC}_{2}$ at $\mathrm{RT}$ and $750^{\circ} \mathrm{C}$ was conducted to compare the tolerance of this material to irradiation damage at different temperatures. Significant increase of the resistance to He irradiation induced swelling and hardening was observed at $750{ }^{\circ} \mathrm{C}$. The bubbles were located in the nano-laminate layers of $\mathrm{Ti}_{3} \mathrm{SiC}_{2}$, whereas the overall crystal structure remained intact at $750{ }^{\circ} \mathrm{C}$. The ability to limit the free growth of He bubbles into larger-sized-spherical shape and the smaller changes of mechanical properties at the higher temperature indicate that $\mathrm{Ti}_{3} \mathrm{SiC}_{2}$ has a good resistance to He effects at high temperatures and that its unique structure can accommodate large amounts of helium in the nano-laminate layer, with its layered structure remaining unchanged.

\section{Acknowledgements}

I. Szlufarska and H. Zhang acknowledge financial support from the US Department of Energy, Basic Energy Science Program under Award \# DEFG02-08ER46493. The authors thank beam line BL14B1 (Shanghai Synchrotron Radiation Facility) for providing the beam time. The authors acknowledge the financial support from China Scholarship Council and the National Nature Science Foundations of China under grant number 11375046 and U1630107.

\section{References}

[1] W. Jeitschko, H. Nowotny, Die Kristallstruktur von Ti3SiC2-ein neuer Komplexcarbid-Typ, Monatshefte Für Chemie. 98 (1967) 329-337. doi:10.1007/BF00899949.

[2] M.W. Barsoum, T. El-Raghy, C.J. Rawn, W.D. Porter, H. Wang, E.A. Payzant, C.R. Hubbard, Thermal properties of Ti3SiC2, J. Phys. Chem. Solids. 60 (1999) 429-439. doi:10.1016/S00223697(98)00313-8.

[3] R. Su, H. Zhang, D.J. O’Connor, L. Shi, X. Meng, H. Zhang, Deposition and characterization of Ti2AlC MAX phase and Ti3AlC thin films by magnetron sputtering, Mater. Lett. 179 (2016) 194-197. doi:10.1016/j.matlet.2016.05.086.

[4] R. Su, H. Zhang, X. Meng, L. Shi, C. Liu, Synthesis of Cr2AlC thin films by reactive magnetron sputtering, Fusion Eng. Des. 125 (2017) 562-566. doi:10.1016/j.fusengdes.2017.04.129.

[5] R. Su, H. Zhang, L. Shi, Deposition of Ti2AlC thin film, in: Trans. Am. Nucl. Soc., 2017: pp. 
$468-471$.

[6] S. Myhra, J.W.B. Summers, E.H. Kisi, Ti3SiC2 - a layered ceramic exhibiting ultra-low friction, Mater. Lett. 39 (1999) 6-11. doi:10.1016/S0167-577X(98)00206-7.

[7] M.W. Barsoum, T. El-Raghy, Synthesis and characterization of a remarkable ceramic: Ti3SiC2, J. Am. Ceram. Soc. 79 (1996) 1953-1956. doi:10.1111/j.1151-2916.1996.tb08018.x.

[8] D.J. Tallman, E.N. Hoffman, E.N. Caspi, B.L. Garcia-Diaz, G. Kohse, R.L. Sindelar, M.W. Barsoum, Effect of neutron irradiation on select MAX phases, Acta Mater. 85 (2015) 132-143. doi:10.1016/j.actamat.2014.10.068.

[9] D.J. Tallman, L. He, B.L. Garcia-Diaz, E.N. Hoffman, G. Kohse, R.L. Sindelar, M.W. Barsoum, Effect of neutron irradiation on defect evolution in Ti3SiC2 and Ti2AlC, J. Nucl. Mater. 468 (2016) 194-206. doi:10.1016/j.jnucmat.2015.10.030.

[10] Q. Huang, R. Liu, G. Lei, H. Huang, J. Li, S. He, D. Li, L. Yan, J. Zhou, Q. Huang, Irradiation resistance of MAX phases Ti3SiC2 and Ti3AlC2: Characterization and comparison, J. Nucl. Mater. 465 (2015) 640-647. doi:10.1016/j.jnucmat.2015.06.056.

[11] H.H. Shen, F.Z. Li, H.B. Zhang, S.M. Peng, X.T. Zu, K. Sun, Effects of Xe+ irradiation on Ti3SiC2 at RT and $500{ }^{\circ} \mathrm{C}$, J. Eur. Ceram. Soc. 37 (2017) 855-858. doi:10.1016/j.jeurceramsoc.2016.08.026.

[12] D.J. Tallman, L. He, J. Gan, E.N. Caspi, E.N. Hoffman, M.W. Barsoum, Effects of neutron irradiation of Ti3SiC2 and $\mathrm{Ti} 3 \mathrm{AlC} 2$ in the $121-1085^{\circ} \mathrm{C}$ temperature range, J. Nucl. Mater. 484 (2017) 120-134. doi:10.1016/j.jnucmat.2016.11.016.

[13] H. Zhang, J.Y. Kim, R. Su, P. Richardson, J. Xi, E. Kisi, J. O’Connor, L. Shi, I. Szlufarska, Defect behavior and radiation tolerance of MAB phases (MoAlB and Fe2AlB2) with comparison to MAX phases, Acta Mater. 196 (2020) 505-515. doi:10.1016/j.actamat.2020.07.002.

[14] P.D. Edmondson, C.M. Parish, Y. Zhang, A. Hallén, M.K. Miller, Helium bubble distributions in a nanostructured ferritic alloy, J. Nucl. Mater. 434 (2013) 210-216. doi:10.1016/j.jnucmat.2012.11.049.

[15] H. Xie, N. Gao, K. Xu, G.H. Lu, T. Yu, F. Yin, A new loop-punching mechanism for helium bubble growth in tungsten, Acta Mater. 141 (2017) 10-17. doi:10.1016/j.actamat.2017.09.005.

[16] F. Sefta, K.D. Hammond, N. Juslin, B.D. Wirth, Tungsten surface evolution by helium bubble nucleation, growth and rupture, Nucl. Fusion. 53 (2013). doi:10.1088/0029-5515/53/7/073015.

[17] H. Zhang, W. Zhang, R. Su, H. Tu, L. Shi, J. Hu, Deuterium trapping in the carbon-silicon codeposition layers prepared by RF sputtering in D2 atmosphere, J. Nucl. Mater. 501 (2018) 217223. doi:10.1016/j.jnucmat.2018.01.037.

[18] H. Zhang, R. Su, L. Shi, D.J. O'Connor, B. V. King, E.H. Kisi, The damage evolution of He 
irradiation on $\mathrm{Ti} 3 \mathrm{SiC} 2$ as a function of annealing temperature, J. Eur. Ceram. Soc. 38 (2018) 1253-1264. doi:10.1016/j.jeurceramsoc.2017.11.041.

[19] H. Zhang, R. Su, L. Shi, D.J.D.J. O'Connor, H. Wen, Structural changes of Ti3SiC2 induced by helium irradiation with different doses, Appl. Surf. Sci. 434 (2018) 1210-1216. doi:10.1016/j.apsusc.2017.11.170.

[20] H. Zhang, R. Su, L. Shi, D.J.J. O'Connor, Helium irradiation tolerance of Ti3SiC2 MAX phase material, in: Trans. Am. Nucl. Soc., American Nuclear Society, 2017: pp. 465-467.

[21] P. Song, J. Sun, Z. Wang, M. Cui, T. Shen, Y. Li, L. Pang, Y. Zhu, Q. Huang, J. Lü, Irradiation resistance properties studies on helium ions irradiated MAX phase Ti3AlC2, Nucl. Instruments Methods Phys. Res. Sect. B Beam Interact. with Mater. Atoms. 326 (2014) 332-336. doi:10.1016/j.nimb.2013.10.046.

[22] M.K. Patel, D.J. Tallman, J.A. Valdez, J. Aguiar, O. Anderoglu, M. Tang, J. Griggs, E. Fu, Y. Wang, M.W. Barsoum, Effect of helium irradiation on Ti3AlC2 at $500^{\circ} \mathrm{C}$, Scr. Mater. 77 (2014) 1-4. doi:10.1016/j.scriptamat.2013.12.010.

[23] H.H. Shen, L. Ao, F.Z. Li, S.M. Peng, H.B. Zhang, K. Sun, X.T. Zu, He+ irradiation induced cracking and exfoliating on the surface of Ti3AlC2, J. Nucl. Mater. 485 (2017) 262-272. doi:10.1016/j.jnucmat.2016.12.022.

[24] R. Su, H. Zhang, L. Shi, H. Wen, Formation of nanostructures in Ti2AlC induced by hightemperature helium irradiation, J. Eur. Ceram. Soc. 39 (2019) 1993-2002. doi:10.1016/j.jeurceramsoc.2019.01.056.

[25] H. Zhang, X. Tang, L. Shi, Elastic recoil cross section determination of $1 \mathrm{H}$ by $4 \mathrm{He}$ ions at $30^{\circ}$ and energy range of 1.6-6.0 MeV, Nucl. Instruments Methods Phys. Res. Sect. B Beam Interact. with Mater. Atoms. 335 (2014) 85-88. doi:10.1016/j.nimb.2014.06.012.

[26] J.F. Ziegler, M.D. Ziegler, J.P. Biersack, SRIM - The stopping and range of ions in matter (2010), Nucl. Instruments Methods Phys. Res. Sect. B Beam Interact. with Mater. Atoms. 268 (2010) 1818-1823. doi:10.1016/j.nimb.2010.02.091.

[27] M. Amer, M.W. Barsoum, T. El-Raghy, I. Weiss, S. Leclair, D. Liptak, The Raman spectrum of Ti3SiC2, J. Appl. Phys. 84 (1998) 5817-5819. doi:10.1063/1.368849.

[28] L. Zhang, Q. Qi, L.Q. Shi, D.J. O’Connor, B. V. King, E.H. Kisi, D.K. Venkatachalam, Damage tolerance of Ti3SiC2 to high energy iodine irradiation, Appl. Surf. Sci. 258 (2012) 6281-6287. doi:10.1016/j.apsusc.2012.03.022.

[29] D. Rodney, G. Martin, Dislocation pinning by small interstitial loops: A molecular dynamics study, Phys. Rev. Lett. 82 (1999) 3272-3275. doi:10.1103/PhysRevLett.82.3272.

[30] J. Friedel, CXXX. On the linear work hardening mate of face-centred cubic single crystals, London, Edinburgh, Dublin Philos. Mag. J. Sci. 46 (1955) 1169-1186. 
doi:10.1080/14786441108520630.

[31] F. Kroupa, P.B. Hirsch, Elastic interaction between prismatic dislocation loops and straight dislocations, Discuss. Faraday Soc. 38 (1964) 49-55. doi:10.1039/DF9643800049.

[32] H.L. Heinisch, F. Gao, R.J. Kurtz, E.A. Le, Interaction of helium atoms with edge dislocations in $\alpha$-Fe, J. Nucl. Mater. 351 (2006) 141-148. doi:10.1016/j.jnucmat.2006.02.027.

[33] N. Li, E.G. Fu, H. Wang, J.J. Carter, L. Shao, S.A. Maloy, A. Misra, X. Zhang, He ion irradiation damage in Fe/W nanolayer films, J. Nucl. Mater. 389 (2009) 233-238. doi:10.1016/j.jnucmat.2009.02.007.

[34] J.H. Evans, An interbubble fracture mechanism of blister formation on helium-irradiated metals, J. Nucl. Mater. 68 (1977) 129-140. doi:10.1016/0022-3115(77)90232-X.

[35] C.S. Murthy, P.K. Swaminathan, Monte Carlo simulations of helium bubble states, J. Chem. Phys. 90 (1989) 2776-2782. doi:10.1063/1.455925.

[36] L. Pizzagalli, M.L. David, Atomistic simulations of a helium bubble in silicon carbide, J. Nucl. Mater. 531 (2020) 151990. doi:10.1016/j.jnucmat.2020.151990.

[37] H. Trinkaus, B.N. Singh, Helium accumulation in metals during irradiation - Where do we stand?, J. Nucl. Mater. 323 (2003) 229-242. doi:10.1016/j.jnucmat.2003.09.001.

[38] G.E. Lucas, The evolution of mechanical property change in irradiated austenitic stainless steels, J. Nucl. Mater. 206 (1993) 287-305. doi:10.1016/0022-3115(93)90129-M.

[39] Q. Song, P. Zhang, J. Zhuang, X.J. Ning, Migrating and clustering of He atoms in Ti3SiC2: Firstprinciples calculations, Comput. Mater. Sci. $137 \quad$ (2017) 327-331. doi:10.1016/j.commatsci.2017.06.004.

[40] H.F. Zhang, B.D. Yao, L.Q. Shi, D.J. O’Connor, J. Huang, J.Y. Zhang, W. Ding, Y.X. Wang, Roles of silicon-layer in $\mathrm{Ti3SiC} 2$ materials response to helium irradiation: New insights from first-principles calculation, Acta Mater. 97 (2015) 50-57. doi:10.1016/j.actamat.2015.07.015.

[41] S.C. Middleburgh, G.R. Lumpkin, D. Riley, Accommodation, accumulation, and migration of defects in Ti3SiC2 and Ti3AlC2 MAX phases, J. Am. Ceram. Soc. 96 (2013) 3196-3201. doi:10.1111/jace.12537.

[42] M.A. Tunes, R.W. Harrison, S.E. Donnelly, P.D. Edmondson, A Transmission Electron Microscopy study of the neutron-irradiation response of Ti-based MAX phases at high temperatures, Acta Mater. 169 (2019) 237-247. doi:10.1016/j.actamat.2019.02.046. 